\title{
The effect of esthetic crown lengthening on perceptions of a patient's attractiveness, friendliness, trustworthiness, intelligence, and self-confidence
}

Samuel Lyon Malkinson

Virginia Commonwealth University

Follow this and additional works at: https://scholarscompass.vcu.edu/etd

Part of the Dentistry Commons

(C) The Author

\section{Downloaded from}

https://scholarscompass.vcu.edu/etd/2689

This Thesis is brought to you for free and open access by the Graduate School at VCU Scholars Compass. It has been accepted for inclusion in Theses and Dissertations by an authorized administrator of VCU Scholars Compass.

For more information, please contact libcompass@vcu.edu. 
The effect of esthetic crown lengthening on perceptions of a patient's attractiveness, friendliness, trustworthiness, intelligence, and self-confidence

A thesis submitted in partial fulfillment of the requirements for the degree of Master of Science in Dentistry at Virginia Commonwealth University.

\title{
By
}

\section{SAMUEL LYON MALKINSON}

BSc McGill University 2003, DMD McGill University 2007

\begin{abstract}
Director: Thomas C. Waldrop, Professor, Director Graduate Periodontics, Department of Periodontics
\end{abstract}

Virginia Commonwealth University

Richmond, Virginia

May, 2012 
$\underline{\text { Table of Contents }}$

Acknowledgment.........................................................................

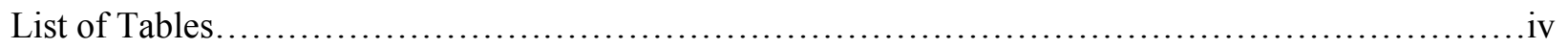

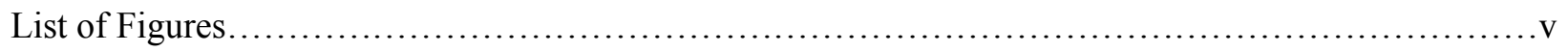

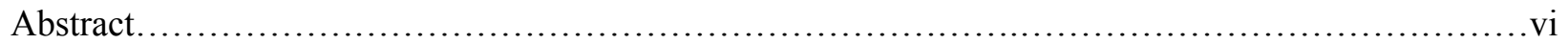

Chapter

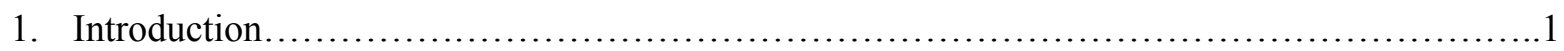

2. Materials and Methods................................................................

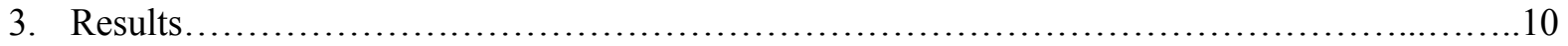

4. Discussion...................................................................... 14

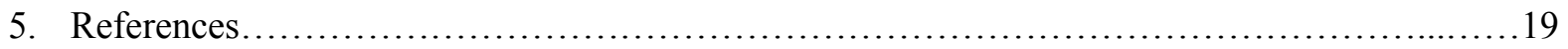




\section{Acknowledgment}

The primary author would like to thank his Research Committee of Dr. Waldrop, Dr. Lanning, and Dr. Sabatini for providing both insight and oversight with this project, and especially Dr. Gunsolley, for his painstaking and thorough work with the statistics. Faye Miles and Shelby Haynes, Dr. Michael Healy and Chris Ray were a great aid with logistics. 


\section{List of Tables}

Table 1: Differences in scores for social parameters between before and after patient pictures, for both

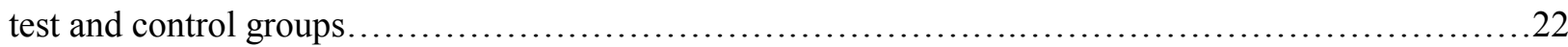

Table 2: Differences in scores for social parameters between test and control groups, for both before and

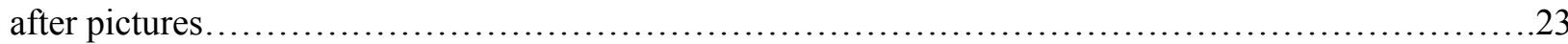

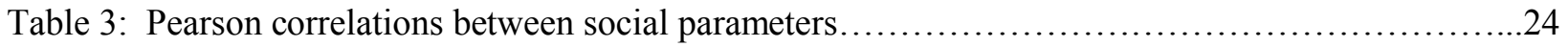




\section{List of Figures}

Figure 1: Coslet's proposed classification for altered passive eruption..............................25

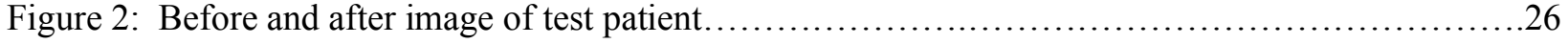

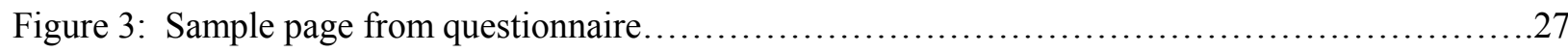

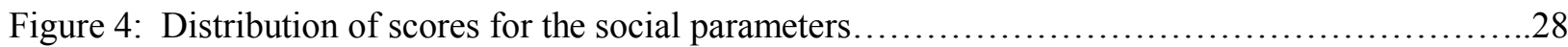




\begin{abstract}
$\underline{\text { Abstract }}$
THE EFFECT OF ESTHETIC CROWN LENGTHENING ON PERCEPTIONS OF A PATIENT'S ATTRACTIVENESS, FRIENDLINESS, TRUSTWORTHINESS, INTELLIGENCE, AND SELF-CONFIDENCE
\end{abstract}

By Samuel Lyon Malkinson, DMD

A thesis submitted in partial fulfillment of the requirements for the degree of Master of Science in Dentistry at Virginia Commonwealth University.

Virginia Commonwealth University 2012

Major Director: Thomas C. Waldrop, Professor, Director Graduate Periodontics, Department of Periodontics

BACKGROUND: Smile esthetics play a major role in the perception of a person's attractiveness, as well as other social parameters. The study aim was to see if altering the gingival display of patients would affect perceptions of the aforementioned social parameters.

METHODS: Smiling photographs were taken and then digitally altered so as to lengthen the teeth and reduce the amount of gingiva. These photographs were shown to a group of senior dental students, and a group of evaluators with no formal dental training. Groups were asked to rate each picture's attractiveness, friendliness, trustworthiness, intelligence, and self-confidence.

RESULTS: The digitally altered photographs were rated higher for all five social parameters than were their unaltered counterparts $(\mathrm{p}<0.0001)$. There were no statistically significant differences between the two groups of evaluators. 
CONCLUSIONS: Excessive gingival display positively affected how attractive a person's smile is judged, and also how friendly, trustworthy, intelligent, and self-confident they are. 


\section{INTRODUCTION}

"Beauty is power; a smile is its sword." Thus quipped Charles Reade, the British playwright and novelist. That he made this astute social commentary in $19^{\text {th }}$ century England only serves to demonstrate how universal a concept it is. In fact, research has shown that agreement on attractiveness ratings is consistent even between different cultures, suggesting a core human perception of what constitutes beauty. ${ }^{1,2}$ Within the face, the mouth carries nearly a third of the importance in the hierarchy of factors that determine whether or not a person is judged to be attractive. ${ }^{3}$ As dentists, esthetics are one of the pillars of the clinical treatment we deliver, along with form and function. Some characteristics of an esthetic smile include: the dental midline is straight, the smile line follows the convexity of the lower lip, the central incisors are symmetrical, the gingival margins of the central incisors are symmetrical, incisal embrasures gradually deepen from central incisors to canines, teeth are straight or mesially inclined, and the width-to-length ratio of the central incisors is $75-80 \%{ }^{4}$ There are also other factors influencing the esthetics of a smile, including incisor show and gingival display. ${ }^{5-10}$ Additionally, the background knowledge of the observer who is perceiving the smile, i.e. whether said observer is a dental professional or a layperson, also has an effect. ${ }^{6,7}$ Research has demonstrated that a subject's smile can influence his or her perceived beauty., ${ }^{5,9}$ A person's smile affects perception by others, as well as self-perception, and may exert a psychosocial influence on the person. Relationships have been identified between personality traits of emotional stability, self-esteem, 
and dominance, and how attractive a person's smile is. ${ }^{10}$ Another study highlighted that people with faces which had high "background attractiveness" were judged to be of a higher social class and of a higher level of sexual attraction. ${ }^{11}$ Other studies have pointed to the fact that people of attractive facial appearance were thought more desirable as dating partners, more successful in their careers, and were recommended for lighter sentences by a mock jury. ${ }^{12-16}$ Finally, Berscheid et al. found that most Americans believe that dental appearance is "very important" in social interactions. $^{17}$

Studies have implied that the attractiveness of an individual may influence personality development and social interaction. ${ }^{18}$ Attractive individuals have been shown to be judged more positively, whereas unattractive individuals have been assigned more negative characteristics. $^{12,18}$ Further studies have shown that appearance is related to a person's leadership status, and that core traits such as friendliness, sincerity, openness to experience, agreeableness, conscientiousness, intelligence, honesty and extraversion are related to leadership. ${ }^{19-21}$ In light of these associations, it seems appropriate to identify any possible means of optimizing a person's smile, the better to serve them in their continual pursuits of forming meaningful relationships with people and building rewarding careers.

A proposed major esthetic problem in dentistry is what is termed excessive gingival display, better known by laypeople as a "gummy smile". The prevalence of excessive gingival display has been estimated at $10 \%$ of the population between the age of 20 and 30 years, and it is seen more in women than in men. ${ }^{22,23}$ Possible etiologic factors for this clinical presentation include gingival enlargement/overgrowth, altered passive eruption, short clinical crowns, vertical maxillary excess, or a short upper lip, or combinations of these conditions. ${ }^{24-26}$ It is very important for clinicians to perform a complete clinical and radiographic exam in order to 
properly identify the etiology or etiologies of the problem. If the gummy smile exists because of gingival overgrowth, perhaps secondary to certain medications, there will be probing depth evident at the relevant sites. If the crowns appear clinically short because of excessive wear from a traumatogenic occlusion, then telltale wear facets and mobility might be present, as well as widened periodontal ligaments radiographically. If the etiology is related to excessive vertical formation of maxillary bone, then performing a lateral cephalometric radiographic study may yield the true diagnosis. A wide variety of therapeutic approaches may be considered, depending on the diagnosis. These may vary from simple procedures such as gingivectomy, to more complex procedures such as raising mucoperiosteal flaps and perform osteoplasty and ostectomy on the alveolar bone,${ }^{27}$ all the way up to having the patient undergo orthognathic surgery.

The specific problem of altered passive eruption warrants special attention. There are two phases of eruption, active and passive. Regarding active eruption, the developing tooth erupts into the oral cavity due to a combination of forces stemming from root formation, the increase in hydrostatic pressure at the periapical level, the mechanisms of selective bone resorption and deposition around the tooth, and the contraction capacity of the periodontal ligament with its cells and fibers. ${ }^{28}$ Active eruption ceases when the teeth come into contact with the opposing dentition. The additional step involved in the normal eruption pattern of teeth involves passive eruption. During tooth formation, the inner enamel epithelium and outer enamel epithelium of the enamel organ fuse after the collapse of stellate reticulum to become the reduced enamel epithelium. This epithelium is the first to come into contact with oral epithelium during eruption, and when the two meet they form the junctional epithelium. This epithelial attachment migrates apically down the sides of the tooth, exposing the crown; this apical migration is known as 
passive eruption. A delay or failure of this to occur can result in the appearance of short clinical crowns and excessive gingival display.

Few studies have attempted to address the reasons for why altered passive eruption may occur. A number of factors have been proposed, such as interocclusal interference on the part of soft tissues during the eruptive phase, the presence of thick and fibrotic gums that tend to migrate more slowly during the passive phase than fine gingival tissue, and even a certain hereditary tendency in families with individuals presenting with altered passive eruption. According to some authors, a bone crest close to the cementoenamel junction could impede gingival migration during the passive phase of eruption. ${ }^{29}$ A $12.1 \%$ incidence of altered passive eruption has been reported from a study of 1025 patients with a mean age of $24.2 \pm 6.2$ years. ${ }^{30}$ A classification for altered passive eruption was suggested by Coslet et al (figure 1): ${ }^{31}$

- Type 1A: excessive amount of keratinized gingiva with normal alveolar crest-to-CEJ relationship

- Type 1B: excessive amount of keratinized gingiva with osseous crest at the CEJ level

- Type 2A: normal amount of keratinized gingiva with normal alveolar crest-to-CEJ relationship

- Type 2B: normal amount of keratinized gingiva with osseous crest at the CEJ level

When treating isolated cases of altered passive eruption, by working with the shape and contour of the gingiva through surgical crown lengthening procedures, a more esthetic final result is possible, whether or not the teeth in question are to have restorations placed upon them. ${ }^{32}$ Crown lengthening is also used to alter the gingival labial profiles, ${ }^{33}$ which have been shown to be an important determinant in perception of an esthetic smile. This alteration has been shown to be perceived differently by dental professionals and laypeople. ${ }^{34}$ Senior dental students close to graduation represent an excellent balance between having acquired as much experience as a 
student can before graduating, and still being close enough to their didactic courses that they remember how to approach the evaluation of these cases. One of the aims of this study is to determine whether an untrained individual (a potential employer in the corporate world, a juror, etc.) can make the same esthetic judgments, and whether they lead to the same kinds of conclusions regarding social parameters.

Because of the potentially significant impact on esthetics of the "gummy smile" due to altered passive eruption and the ability of dental professionals to treat it, and the more broad social context, the aims of this research were twofold: first, to see if there is any difference in people's perceptions of social parameters such as attractiveness, friendliness, trustworthiness, intelligence, and self-confidence, when looking at before- and after-treatment photographs of "gummy smiles", and then second, to see if there is any difference in this perception between senior dental students and laypersons. 


\section{MATERIALS AND METHODS}

\section{Preparation of Survey Items}

Following an exemptions from Virginia Commonwealth University's Institutional Review Board (IRB) approval, a survey was constructed using pre-operative facial frontal smiling photographs of ten individuals, "simulated patients" cropped to exclude facial features not pertaining to the mouth, so as not to introduce unnecessary confounding variables. ${ }^{6}$ The pre-operative photographs were the control photographs. These "patients" were identified from the students and support staff of the School of Dentistry. In each case, the patient in question was diagnosed as having altered passive eruption in the anterior maxilla. The patient sample of individuals consisted of three males and seven females. Two females and one male were African-American. The remaining patients, five females and two males, were Caucasian. This was intended to represent an approximate cross-section of the population of the greater Richmond area, VA. In this study, all future references to "patients" refer to those individuals who had pictures taken of their mouths, while all references to "subjects" or "evaluators" refer to the control and test groups of students who were filling out the survey questionnaires regarding the aforementioned pictures. 


\section{Survey Construction}

The patients' pre-operative photographs were digitally altered, using Adobe Photoshop CS5 ${ }^{\circledR}$, to produce a projected version of what the patient would look like after an esthetic crown lengthening surgery (figure 2). The modifications were thus limited to varying the heights of the zeniths of the gingival margins and the flatness of the gingival margins. These photographs were

the test photographs. Thus a total of 20 photographs were a part of the survey. ${ }^{35}$ An electronic survey was constructed using the patients' photographs, which were placed in random order as per a sequence generated by a computer program on the website www.random.org. These pictures were placed in this random order in a Microsoft PowerPoint ${ }^{\circledR}$ presentation. This presentation was shown to groups of research subjects in lecture halls, by being projected onto a big screen. Explanations were delivered verbally at the beginning of the study, and the investigator remained with the subjects to ensure they had no questions on how to complete the study. The subjects were made to fill out paper questionnaires, starting with their gender, age, race/ethnicity, and whether they were a senior dental student or a student who had completed no formal education in dentistry. For each individual photograph, there were five statements proposed on a page of the questionnaire. The statements were:

\section{This person is attractive}

2. This person is friendly

3. This person is trustworthy

4. This person is intelligent

5. This person is self-confident

Subjects indicated their level of agreement or disagreement with each statement via a Visual Analog Scale (VAS) (figure 3). This consisted of a horizontal line with gradations, exactly 
$100 \mathrm{~mm}$ in length. On the left side of this line was the word "Disagree", and on the right side was the word "Agree." Subjects were instructed to place an "X" on this line, which allowed the researcher to assign a numerical value to the subjects' responses. The answer recorded was a value between 0 and 100 .

III. Identification of subjects.

The survey was administered to two groups of subjects. The first group were senior dental students. This comprised the control group, which had received formal training in recognition of excessive gingival display and in the diagnosis of altered passive eruption. The second group, the test group of laypeople, consisted of members of what is known at VCU as D0.5 students, who are students that have been provisionally accepted to dental school but have not begun their formal dental training any further than basic science courses, and additionally a group of first year medical students, for whom their curriculum does not include lectures regarding dental esthetics. Subjects were identified by means of mass e-mails and announcements made over the School of Dentistry's intercom system, and the study was conducted from December 2011January 2012.

\section{Statistical methods}

The responses of the subjects were measured with a standard metric ruler, and the level of agreement was measured as an integer between 1 and 100. The measurement was performed from the start of the dotted line of the VAS until the point at which the center of the marked X crossed the dotted line. These values were recorded into a database on a Microsoft Excel ${ }^{\circledR}$ spreadsheet. As each subject evaluated each patient before and after the digital editing of the 
images, each subject evaluated 20 images. This resulted in a repeated measures design for two factors, the 'patient' and the 'subject'.

The distributions of the outcome variables were evaluated. While the distributions did not assume a normal distribution when evaluated with the Shapiro-Wilk W Test, the distributions were nearly normally distributed when assessed visually (figure 4). Since there were a large number of evaluations (1540), parametric methods were used due to assumptions about the distribution of mean responses under the central limit theorem.

To analyze the effect of editing the images, potential covariates of race and gender of both the patients and the subjects, and age of the subjects, ANOVA was used. The ANOVA model included two random effects (one for the patients and one for the subjects), along with the fixed effects previously described. To evaluate the relationship between the five outcome variables, Pearson correlation coefficients were calculated (JMP 9.0Pro ${ }^{\circledR}$, SAS Institute, Cary NC). The level of significance was set at $\mathrm{p}<0.05$. 


\section{RESULTS}

I. Description of the sample population.

Seventy-seven subjects completed the study questionnaire. The control group had $n=43$, and were all senior dental students. For the test group, 7 were dental students just entering dental school (and thus without any formal training on the subject of smile esthetics), and 27 were first year medical students. The 7 beginner dental students and the medical students were pooled together for all the statistical analyses, for the test group to have $n=34$. Of the control group of senior dental students, 19 were female $(44 \%)$ and 24 were male $(56 \%)$. The mean age of the senior dental students was 27.5 \pm 3.6 . Thirty-five subjects in the senior dental student group reported being Caucasian (81\%), 5 reported being Asian (11.5\%), 2 reported being AfricanAmerican (4.5\%) and 1 reported being Other (3\%). Of the test group, 19 were female (56\%) and 15 were male $(44 \%)$. The mean age of the test group was $24.6 \pm 3.9 .18$ subjects in the test group reported being Asian (53\%), 15 reported being Caucasian (44\%), and 1 reported being Other $(3 \%)$.

II. Effect of digital "crown lengthening" on subjects' perceptions of attractiveness friendliness, trustworthiness, intelligence, and self-confidence

The scores for all the picture ratings were reported as a number on a scale of $0-100$. The least square mean scores for the evaluations of the patients, both before and after the digital 
alterations, and by both the control group and the test group are shown in Table 1. When comparing the control and test pictures within groups, for all 5 social parameters, the least square mean scores increased from the control pictures to the digitally altered test pictures. For the parameter attractiveness, subjects rated the digitally crown lengthened pictures higher than the before pictures $(59.1 \pm 3.9$ vs. $51.6 \pm 3.9)$. For the parameter friendliness, subjects rated the digitally crown lengthened pictures higher than the before pictures (68.7 \pm 3.4 vs. $65.0 \pm 3.4)$. For the parameter trustworthiness, subjects rated the digitally crown lengthened pictures higher than the before pictures $(63.3 \pm 3.2$ vs. $60.1 \pm 3.2)$. For the parameter intelligent, subjects rated the digitally crown lengthened pictures higher than the before pictures (66.4 \pm 3.4 vs. $62.6 \pm 3.4)$. For the parameter self-confidence, subjects rated the digitally crown lengthened pictures higher than the before pictures ( $70.5 \pm 3.3$ vs. $64.5 \pm 3.3$ ). All these differences were statistically significant (p $<0.0001)$.

III. Effect of subject educational background on subjects' perceptions of attractiveness friendliness, trustworthiness, intelligence, and self-confidence

Table 2 presents the same data, rearranged to compare the control group of senior dental students with the test group of medical students and dental students at the beginning of their studies. With only one exception, the test group always rated the patients higher, on average, for the social parameters than the control group of senior dental students. The largest difference between the groups occurred among the control pictures for the parameter of intelligence, and was a full 4 points. When analyzed alone, none of the differences between the control group's ratings of the pictures and the test group's ratings were statistically significant. An interaction effect was observed between whether or not the subject was a senior dental student and whether or not the 
picture had been digitally altered, but this was only present for the parameter of attractiveness, and the level of significance was borderline $(\mathrm{p}=0.0253)$.

IV. Effect of patient race, gender, on subjects' perceptions of attractiveness friendliness, trustworthiness, intelligence, and self-confidence

Analysis was carried out on the race and gender of the "patient" in the pictures, to see if they had any effect on the outcomes. Regarding the race of the patients, a statistically significant effect was found for parameters trustworthiness and self-confidence, with evaluators ranking AfricanAmericans more trustworthy than Caucasians (64.4 \pm 3.6 vs. $59.0 \pm 3.3)$ and more self-confident than Caucasians ( $71.3 \pm 4.0$ vs. $63.7 \pm 3.4)$. Regarding the gender of the patients, a statistically significant effect was found for the parameters of trustworthiness and intelligence, with subjects rating females more trustworthy than males $(65.3 \pm 3.3$ vs. $58.1 \pm 3.6)$ and more intelligent than males $(68.0 \pm 3.4$ vs. $61.0 \pm 3.8)$.

V. Effect of subject race, gender, and age on subjects' perceptions of attractiveness friendliness, trustworthiness, intelligence, and self-confidence

Analysis was additionally carried out on and the race, gender and age of the subjects from both groups doing the evaluations, to see if they had any effect on the outcomes. Of all these factors, only age had a borderline statistically significant effect, and it was only for the parameter of attractiveness $(\mathrm{p}=0.0263)$.

\section{Correlation between social parameters}

The correlation between how the subjects perceived the patients' attractiveness, friendliness, trustworthiness, intelligence and self-confidence is shown in Table 2. All of the parameters 
showed statistically significant positive correlations with each other $(\mathrm{p}<0.0001)$. Interestingly, the parameter that most frequently had the lowest correlations was attractiveness ( 4 of the 5 lowest correlations involved attractiveness with one of the other parameters). 


\section{DISCUSSION}

The interpretation of the aforementioned results is somewhat subjective, and this is because the very nature of this research is subjective. The results obtained in this study have first of all demonstrated that people can identify not only whether they think a person is attractive, but also whether they think they are friendly, trustworthy, intelligent, and self-confident, all based solely on one aspect of the person's smile. This study was based in part on research that was performed at Virginia Commonwealth University's (VCU) Department of Orthodontics. ${ }^{35,36}$ Research has demonstrated that over $65 \%$ of post-orthodontic patients demonstrate non-ideal width-to-length ratios, and over $60 \%$ demonstrate asymmetries of the gingival margins. ${ }^{37}$

The Orthodontics studies assessed patients for social parameters such as friendliness, trustworthiness, intelligence, self confidence, popularity, athletic ability, and leadership ability. All these concepts are quite nebulous. The real question is whether the altered smiles in those studies led directly to different perceptions in the social parameters in question, or if those perceived differences were because the smiles had been made more attractive. The current study included some of these parameters, but also first asked the question of the subjects doing the evaluations as to how attractive was the smile. The results indicated that attractiveness was positively correlated with the other social parameters. That those correlations tended to be lower than the correlations between the other four social parameters is not surprising, as under the given circumstances, attractiveness is the least nebulous concept. This is because an evaluator 
can identify for themselves things about a person's smile that are attractive or not. If the correlation coefficients between attractiveness and the other social parameters had all approached a value of 1 , then it might have been interpreted that measuring attractiveness and friendliness, trustworthiness, intelligence and self confidence were all measuring the same thing. The implication from the results of the current study is that the perceived improvement in ratings of friendliness, trustworthiness, intelligence and self confidence following the digital alteration in the pictures is because of the perceived improvement in attractiveness.

Another important difference between this study and the VCU Orthodontics studies is the use of the isolated smile for the pictures to be evaluated. In both of the Orthodontics studies, the smiling photographs that were used included a view of the entire face. The disadvantage of this approach is that it gives the evaluator more to work with in terms of making his or her ratings, and it then becomes difficult to isolate whether it was the changes in the smile, as opposed to the eyes, or jaw line, or hair etc. which really steered the rating one way or another. The counter argument to this might be to assert that since the only thing that changes from the control to the test picture is the smile, the presence of everything else in the picture is irrelevant. A fair point, but consider the possibility where the smile in the control picture is so distracting that the evaluator never even gets to the rest of the face, where as in the test picture, when the esthetic smile issue has been addressed, the evaluator might be able to appreciate how it is in harmony with the surrounding facial structures. In order to eliminate this possible effect, the pictures used in this study were frontal smiling photographs that were focused on the lower face, to include no higher than the bottom of the nose and no lower than the menton of the chin. The subjects apparently had no difficulty evaluating the pictures in question, despite the reduced field of view. 
The digital esthetic crown lengthening performed on the patients in the current study led to higher ratings of all five social parameters. The digital alterations were performed in such a manner that nothing other than the heights of the gingival zeniths were altered, and this was done to isolate the effect of esthetic crown lengthening. This was performed in contrast to the experimental protocol of another similar study, ${ }^{38}$ which instead digitally "treated" patients by moving their entire dental unit apically without changing the ratio of the height to the width, as was done in our study. That study, however, did find very similar results in terms of higher ratings for attractiveness for the digitally altered pictures. Perhaps the patients in that study had excessive gingival display of an etiology other than altered passive eruption, since merely changing the apico-coronal position of the crown would not have treated the underlying cause.

Another interesting difference worth discussing that relates to the study by Ioi et al. ${ }^{38}$ is the subject population. That study was performed in Japan, and the two groups who rated the pictures were dental students and practicing orthodontists, neither of whom could be considered laypeople. It had already been established that dental professionals can pick up on esthetic parameters of a patient's smile. It was for this reason that the control group was chosen to be senior dental students, for whom the training and didactic education is still fresh. The test group was chosen to be students with no formal dental training. The sample population identified consisted of members of what is known at VCU as D0.5 students, who are students that have been provisionally accepted to dental school but have not initiated their formal dental training beyond the basic science courses, and additionally a group of first year medical students, whose curriculum does not include lectures regarding dental esthetics. Despite this group's lack of formal training, they were able to perceive differences in attractiveness, friendliness, trustworthiness, intelligence and self confidence just as well as the senior dental students. This 
finding may well be the most significant of the study, as the subtext reveals that any person can make subjective decisions about whether or not they find an individual attractive based on their smile, and whether or not this affects how friendly, trustworthy, intelligent and self-confident they perceive the individual to be.

Finally, despite efforts to isolate gingival display as the main factor affecting the outcomes, statistical analysis revealed that the race and gender of the patient being evaluated affected the results. Regarding both gender and race, evidence can sometimes be contradictory. For example, one study found that despite there being no statistically significant difference in actual IQ values between men and women, women perceived their IQ to be lower than men's. ${ }^{39,40}$ In the current study, while the subjects were not self-assessing, women were rated as appearing to have higher intelligence than men. Regarding trustworthiness, the results of this study correlate with results obtained in another study, which also found that attractive women were likely to be rated more trustworthy than men. ${ }^{41}$ The results also indicate that African-Americans were rated more trustworthy than Caucasians, even though in another study there was no significant difference between the two on how trustworthy they were rated. ${ }^{42}$ In terms of self-confidence, the results may contradict an assertion made that blacks were significantly less self-confident, ${ }^{43}$ as those pictures of African-Americans were rated higher for self confidence than pictures of Caucasians. Interestingly, in the current study, neither patient gender nor patient race had any effect on whether the pictures were perceived as more or less attractive, despite conflicting evidence in the literature. ${ }^{44,45}$ Further, and again in conflict with published results, neither the gender nor the race of subject doing the evaluation affected the outcome of the ratings. ${ }^{46}$

It should be clear that a "gummy smile" can have an adverse effect on the perception of a patient's attractiveness, friendliness, trustworthiness, intelligence and self-confidence. For any 
dental professional, an assessment of the amount of gingival display is appropriate, as well as an investigation into the etiology of any diagnosed excessive gingival display. While the treatment rationale for this issue is at present more esthetic than it is biologic, the available body of evidence shows that the social parameters associated with an attractive smile are indispensable for healthy interpersonal interaction. After all, as Robert Harling said in his 1987 play Steel Magnolias, "Smile! It increases your face value." 
REFERENCES 


\section{REFERENCES}

1. Bernstein IH, Lin TD, McClellan P. Cross- vs. within-racial judgments of attractiveness. Percept Psychophys. 1982; 32:495-503.

2. Maret SM. Attractiveness ratings of photographs of blacks by Cruzans and Americans. J Psychol 1983; 115:113-116.

3. Goldstein RE. Study of need for esthetics in dentistry. J Prosthet Dent. 1969; 21:589-598.

4. Chiche GJ, Pinault A. Esthetics of Anterior Fixed Restorations. Quintessence Publishing Co. 1994.

5. Flores-Mir C, Silva E, Barriga MI, Lagravere MO, Major PW. Lay person's perception of smile aesthetics in dental and facial views. J Orthod. 2004; 31:204-209.

6. Işiksal E, Hazar S, Akyalçin S. Smile esthetics: perception and comparison of treated and untreated smiles. Am J Orthod Dentofacial Orthop. 2006; 129:8-16.

7. Kokich VO, Kokich VG, Kiyak HA. Perceptions of dental professionals and laypersons to altered dental esthetics: asymmetric and symmetric situations. Am J Orthod Dentofacial Orthop. 2006; 130:141-151.

8. Jørnung J, Fardal Ø. Perceptions of patients' smiles: a comparison of patients' and dentists' opinions. J Am Dent Assoc. 2007;138:1544-1553; quiz 1613-1614.

9. Kerosuo H, Hausen H, Laine T, Shaw WC. The influence of incisal malocclusion on the social attractiveness of young adults in Finland. Eur J Orthod. 1995; 17:505-512. 
10. Van der Geld P, Oosterveld P, Van Heck G, Kuijpers-Jagtman AM. Smile attractiveness. Self-perception and influence on personality. Angle Orthod. 2007;77:759-765.

11. Shaw WC, Rees G, Dawe M, Charles CR. The influence of dentofacial appearance on the social attractiveness of young adults. Am J Orthod. 1985;87:21-26.

12. Dion K, Berscheid E, Walster E. What is beautiful is good. J Pers Soc Psychol. $1972 ; 24: 285-290$.

13. Baldwin DC. Appearance and aesthetics in oral health. Community Dent Oral Epidemiol. $1980 ; 8: 244-256$.

14. Efran MG. The effect of physical appearance on the judgment of guilt, interpersonal attraction and severity of recommended punishment in a simulated jury task. Journal of Research in Personality. 1974;8:45-54.

15. Jacobson A. Psychological aspects of dentofacial esthetics and orthognathic surgery. Angle Orthod. 1984;54:18-35.

16. Miller AG. Role of physical attractiveness in impression formation. Psychonomic Science. 1970;19:241-243.

17. Berscheid E, Walster E, Bohrnstedt G. Body image. Psych Today. 1973;7:119-131.

18. Langlois JH, Kalakanis L, Rubenstein AJ, Larson A, Hallam M, Smoot M. Maxims or myths of beauty? A meta-analytic and theoretical review. Psychol Bull. 2000;126:390423.

19. Cherulnik PD, Turns LC, Wilderman SK. Physical Appearance and Leadership: Exploring The Role of Appearance-Based Attribution in Leader Emergence. J Appl Soc Psychol. 1990;20:1530-1539. 
20. Judge TA, Bono JE, Ilies R, Gerhardt MW. Personality and leadership: a qualitative and quantitative review. J Appl Psychol. 2002;87:765-780.

21. Magee M, Hojat M. Personality profiles of male and female positive role models in medicine. Psychol Rep. 1998;82:547-559.

22. Tjan AH, Miller GD, The JG. Some esthetic factors in a smile. J Prosthet Dent 1984;51:24-28.

23. Peck S, Peck L, Kataja M. The gingival smile line. Angle Orthod 1992;62:91-100.

24. Rosenberg ES, Garber DA, Evian CI. Tooth lengthening procedures. Compend Contin Educ Gen Dent. 1980;1:161-172.

25. Levine RA, McGuire M. The diagnosis and treatment of the gummy smile. Compend Contin Educ Dent. 1997;18:757-764.

26. Dolt AH 3rd, Robbins JW. Altered passive eruption: an etiology of short clinical crowns. Quintessence Int. 1997;28:363-372.

27. Allen EP. Surgical crown lengthening for function and esthetics. Dent Clin North Am. 1993;37:163-179.

28. Alpiste-Illueca F. Altered passive eruption (APE): a little-known clinical situation. Med Oral Patol Oral Cir Bucal. 2011 Jan 1;16(1):e100-104.

29. Evian CI, Cutler SA, Rosenberg ES, Shah RK. Altered passive eruption: the undiagnosed entity. J Am Dent Assoc. 1993;124:107-110.

30. Volchansky A, Cleaton-Jones PE. Delayed passive eruption. A predisposing factor to Vincent's infection? J Dent Asso S Africa 1974;29:291-294.

31. Coslet JG, Vanarsdall R, Weisgold A. Diagnosis and classification of delayed passive eruption of the dentogingival junction in the adult. Alpha Omegan 1977;70:24-28. 
32. Braswell LD. Soft tissue contouring as periodontal plastic surgery. Curr Opin Cosmet Dent. 1997;4:22-28.

33. Sonick M. Esthetic crown lengthening for maxillary anterior teeth. Compend Contin Educ Dent. 1997;18:807-819.

34. An KY, Lee JY, Kim SJ, Choi JI. Perception of maxillary anterior esthetics by dental professionals and laypeople and survey of gingival topography in healthy young subjects. Int J Periodontics Restorative Dent. 2009;29:535-541.

35. Montgomery EB. 'Leadership and dental aesthetics of adults as perceived by laypersons.' (unpublished Master's thesis, Virginia Commonwealth University, 2009).

36. Henson ST. 'The Psychosocial Influence of Dental Esthetics in Adolescents as Judged By Peers' (unpublished Master's thesis, Virginia Commonwealth University, 2009).

37. Konikoff BM, Johnson DC, Schenkein HA, Kwatra N, Waldrop TC. Clinical crown length of the maxillary anterior teeth preorthodontics and postorthodontics. J Periodontol. 2007 Apr;78(4):645-653.

38. Ioi H, Nakata S, Counts AL. Influence of gingival display on smile aesthetics in Japanese. Eur J Orthod. 2010 Dec;32(6):633-637.

39. Furnham A. Sex, IQ, and emotional intelligence. Psychol Rep. 2009 Dec;105(3 Pt 2):1092-1094.

40. Stieger S, Kastner CK, Voracek M, von Stumm S, Chamorro-Premuzic T, Furnham A. Independent effects of personality and sex on self-estimated intelligence: evidence from Austria. Psychol Rep. 2010 Oct;107(2):553-563.

41. Shinners E. Effects of The "What is Beautiful is Good" Stereotype on Perceived Trustworthiness. UW-L Journal of Undergraduate Research XII (2009):1-5. 
42. Stanley DA, Sokol-Hessner P, Banaji MR, Phelps EA. Implicit race attitudes predict trustworthiness judgments and economic trust decisions. Proc Natl Acad Sci U S A. 2011 May 10;108(19):7710-7715.

43. Campbell A, Converse PE, Rodgers WL. The Quality of American Life: Perceptions, Evaluations, and Satisfactions. Russell Sage Foundation. 1976.

44. Perrett, D. I., Lee, K. J., Penton-Voak, I. S., Rowland, D. R., Yoshikawa, S., Burt, D. M., Henzi, S. P., Castles, D. L. \& Akamatsu, S. (1998). Effects of sexual dimorphism on facial attractiveness. Nature, 394, 884-887.

45. Davis DS, Sbrocco T, Odoms-Young A, Smith DM. Attractiveness in African American and Caucasian women: is beauty in the eyes of the observer? Eat Behav. 2010 Jan;11(1):25-32.

46. Yanover T, Thompson JK. Perceptions of health and attractiveness: the effects of body fat, muscularity, gender, and ethnicity. J Health Psychol. 2010 Oct;15(7):1039-1048. 
Table 1: Differences in least square mean scores for social parameters between before and after patient pictures, for both test and control groups

\begin{tabular}{|c|c|c|c|c|c|c|c|c|c|c|c|c|}
\hline \multirow[b]{2}{*}{ Time } & \multirow[b]{2}{*}{ Group } & \multirow[b]{2}{*}{$\mathbf{N}$} & \multicolumn{2}{|c|}{ Attractive } & \multicolumn{2}{|c|}{ Friendly } & \multicolumn{2}{|c|}{ Trustworthy } & \multicolumn{2}{|c|}{ Intelligent } & \multicolumn{2}{|c|}{ Self-confident } \\
\hline & & & Mean & Std Err & Mean & Std Err & Mean & Std Err & Mean & Std Err & Mean & Std Err \\
\hline Before & Dental & 430 & 49.5 & 4.1 & 62.4 & 3.7 & 58.3 & 3.5 & 60.1 & 3.6 & 63.3 & 3.6 \\
\hline After & & 430 & 58.4 & 4.1 & 66.5 & 3.7 & 61.6 & 3.5 & 65.0 & 3.6 & 70.0 & 3.6 \\
\hline Before & Non & 340 & 53.7 & 4.2 & 67.6 & 3.8 & 61.8 & 3.7 & 65.0 & 3.9 & 65.7 & 3.8 \\
\hline After & & 340 & 59.7 & 4.2 & 70.8 & 3.8 & 65.0 & 3.7 & 67.8 & 3.9 & 71.0 & 3.8 \\
\hline
\end{tabular}


Table 2: Differences in least square mean scores for social parameters between test and control groups, for both before and after pictures

\begin{tabular}{|c|c|c|c|c|c|c|c|c|c|c|c|c|}
\hline \multirow{2}{*}{ Time } & \multirow[b]{2}{*}{ Group } & \multirow[b]{2}{*}{$\mathbf{N}$} & \multicolumn{2}{|c|}{ Attractive } & \multicolumn{2}{|c|}{ Friendly } & \multicolumn{2}{|c|}{ Trustworthy } & \multicolumn{2}{|c|}{ Intelligent } & \multicolumn{2}{|c|}{ Self-confident } \\
\hline & & & Mean & Std Err & Mean & Std Err & Mean & Std Err & Mean & Std Err & Mean & Std Err \\
\hline Before & Dental & 430 & 49.5 & 4.1 & 62.4 & 3.7 & 58.3 & 3.5 & 60.1 & 3.6 & 63.3 & 3.6 \\
\hline & Non & 340 & 53.7 & 4.2 & 67.6 & 3.8 & 61.8 & 3.7 & 65.0 & 3.9 & 65.7 & 3.8 \\
\hline After & Dental & 430 & 58.4 & 4.1 & 66.5 & 3.7 & 61.6 & 3.5 & 65.0 & 3.6 & 70.0 & 3.6 \\
\hline & Non & 340 & 59.7 & 4.2 & 70.8 & 3.8 & 65.0 & 3.7 & 67.8 & 3.9 & 71.0 & 3.8 \\
\hline
\end{tabular}


Table 3: Pearson correlations between social parameters (all correlations statistically significant at $\mathrm{p}<0.0001)$

$\begin{array}{ll}\begin{array}{l}\text { Pairwise } \\ \text { Variable }\end{array} & \begin{array}{c}\text { Correlations } \\ \text { by Variable }\end{array} \\ \text { Attractive } & \text { Friendly } \\ \text { Attractive } & \text { Trustworthy } \\ \text { Attractive } & \text { Intelligent } \\ \text { Attractive } & \text { Self-confident } \\ \text { Friendly } & \text { Trustworthy } \\ \text { Friendly } & \text { Intelligent } \\ \text { Friendly } & \text { Self-confident } \\ \text { Trustworthy } & \text { Intelligent } \\ \text { Trustworthy } & \text { Self-confident } \\ \text { Intelligent } & \text { Self-confident }\end{array}$

Correlation
0.56
0.59
0.63
0.59
0.78
0.63
0.67
0.73
0.59
0.64

Lower $95 \%$
0.52
0.56
0.60
0.55
0.76
0.60
0.65
0.71
0.56
0.61

Upper $95 \%$

0.60

0.63

0.66

0.62

0.80

0.66

0.70

0.76

0.62

$\begin{array}{ll}0.61 & 0.67\end{array}$




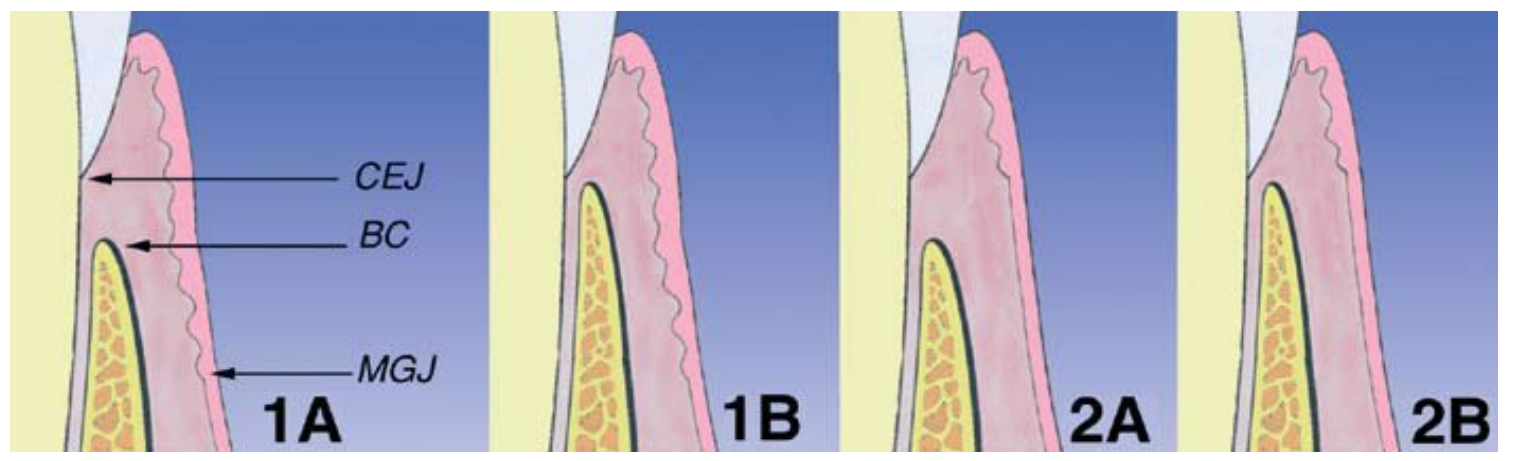

Figure 1: Coslet's proposed classification for altered passive eruption 

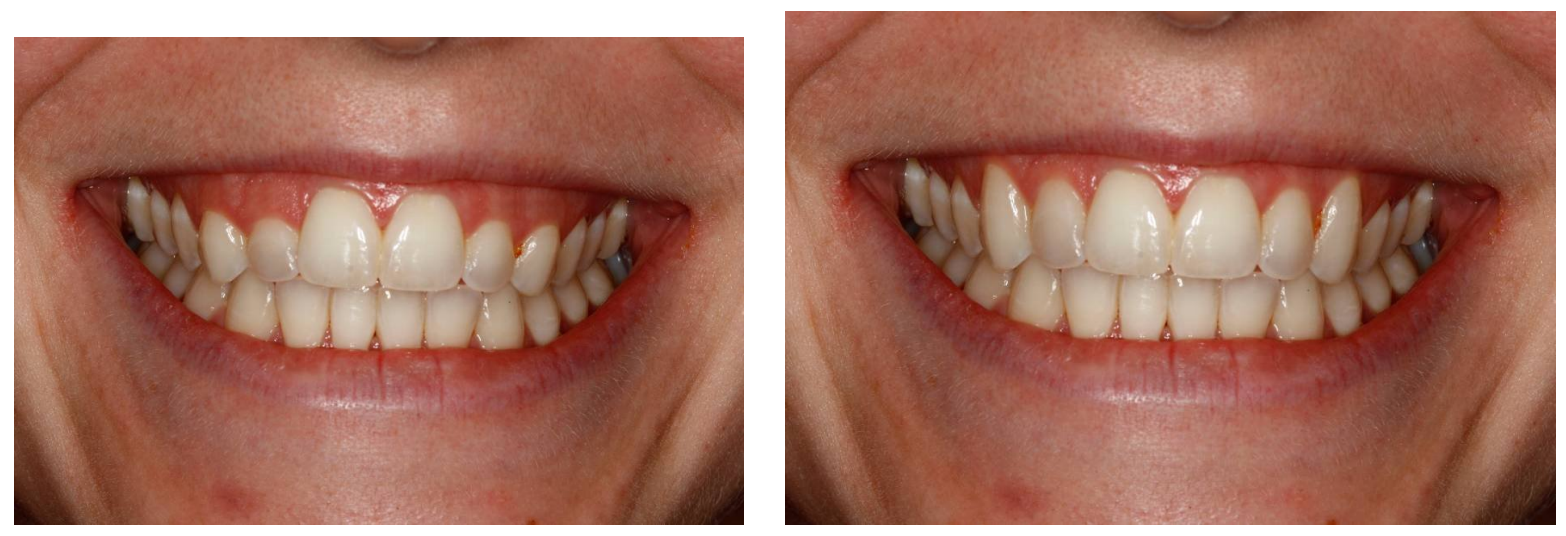

Figure 2: Before and after image of test patient 


\section{Item \#1}

Mark your level of agreement with the statements by placing an $\mathrm{X}$ along the dotted line.

1. This person is attractive.

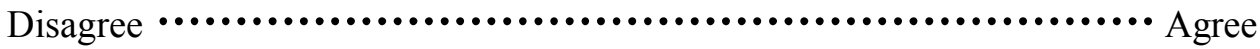

2. This person is friendly.

Disagree.$\ldots \ldots \ldots \ldots \ldots \ldots \ldots \ldots \ldots \ldots \ldots \ldots \ldots \ldots \ldots \ldots \ldots \ldots \ldots \ldots \ldots$. Agree

3. This person is trustworthy.

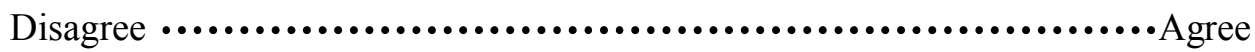

4. This person is intelligent.

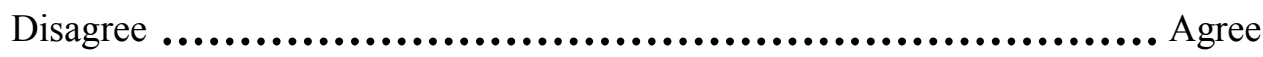

5. This person is self-confident.

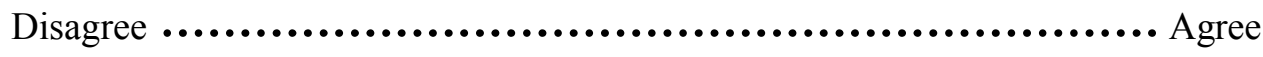

Figure 3: Sample page from questionnaire 


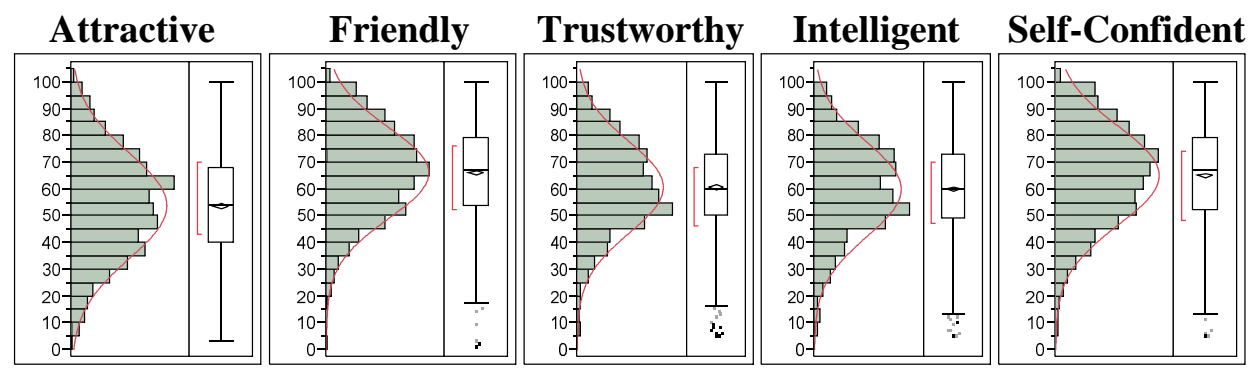

Figure 4: Distribution of scores for the social parameters 